\title{
AS GRAMÁTICAS DE REFERENCIA E ESCOLAR, DE SAID ALI: UM ESTUDO DE CASO SOBRE A GRAMATICOGRAFIA BRASILEIRA DO INÍCIO DO SÉCULO XX
} José Bento Cardoso Vidal Neto*

(iD) https://orcid.org/0000-0002-6713-4914

Como citar este artigo: VIDAL NETO, J. B. C. As gramáticas de referência e escolar, de Said Ali: um estudo de caso sobre a gramaticografia brasileira do início do século XX. Todas as Letras - Revista de Lingua e Literatura, São Paulo, v. 22, n. 2, p. 1-16, maio/ago. 2020. DOI 10.5935/1980-6914/eLETLL2012561

Submissão: junho de 2019. Aceite: setembro de 2019.

Resumo: O presente trabalho tem como objetivo contribuir para a caracterização da gramaticografia brasileira do início do século XX. Nossa hipótese é que a gramática, nesse período, perde a centralidade nas discussões a respeito do Português que possuía até então e passa a ser um tipo de publicação de viés mais escolar. Nesse novo cenário, as discussões mais aprofundadas, dirigidas aos especialistas, aos pares, parecem se deslocar para as obras de caráter monográfico, que passam a ser cada vez mais publicadas. Para essa empreitada, realizamos um estudo pontual utilizando duas gramáticas de Said Ali, a Secundaria (1923) e a Historica (1931). Em termos teórico-metodológicos, utilizamos os pressupostos presentes em Swiggers (2004).

Palavras-chave: Historiografia linguística. Gramaticografia brasileira. Said Ali. Século XX. Epistemologia gramatical. 


\section{INTRODUÇÃo}

O

presente artigo tem como objetivo apresentar resultados parciais da pesquisa de doutorado que vem sendo desenvolvida por nós desde o início de 2016, sob o título de A formação do pensamento linguistico brasileiro: entre a gramática e as novas possibilidades de tratamento da lingua (1900-1940)1.

A investigação que estamos desenvolvendo pode ser assim sintetizada: compreender qual foi o papel que a gramática desempenhou no quadro de reflexões sobre a língua portuguesa no Brasil do início do século XX, considerando o crescimento de outros tipos de publicação editorial, como os livros ou opúsculos de caráter monográfico, as teses produzidas para concursos de cátedra nos colégios mais prestigiados das grandes cidades, ensaios sobre questões pontuais da lingua, entre outros.

As análises preliminares das fontes que compõem o presente trabalho apontam para uma característica marcante da produção linguística brasileira do início do século XX: o crescimento das obras de caráter monográfico e também das gramáticas escolares. De acordo com nossa hipótese, esse crescimento alterará o papel central ocupado pela gramática até fins do século XIX, fazendo que ela se torne uma obra de viés mais escolar, deixando, assim, para as obras monográficas, a discussão linguístico-gramatical mais aprofundada, dirigida aos especialistas da área, aos pares.

Objetivamos, portanto, a partir dessa constatação de perda da centralidade da gramática, verificar para onde foi deslocada a discussão especializada sobre o português, investigando, para isso, além das gramáticas, esse universo mais amplo de obras aqui já apontado.

\section{OPÇÕES TEÓRICO-METODOLÓGICAS}

Para a nossa pesquisa, em termos analiticos, nos interessa o modelo proposto por Swiggers (2004, p. 133-134, tradução nossa), que afirma ser possivel distinguir a dinâmica da história da linguística em quatro camadas (teórica, técnica, documental e contextual/institucional).

A camada teórica corresponde à visão global sobre a linguagem, à concepção de tarefas e estatutos da linguística; a camada técnica inclui as técnicas de análise (linguística/gramatical) e os métodos de apresentação dos dados; a camada documental corresponde à documentação linguística e filológica (número de idiomas, tipos de fontes e dados) sobre a qual se baseia o estudo linguístico; a camada contextual e institucional (esta última se torna mais importante à medida que nos aproximamos da era moderna) da reflexão e da prática linguísticas.

Para o autor, "o pensamento linguístico é algo muito complexo" e essa múltipla abordagem (das camadas) garante uma análise mais completa e adequada para a historiografia da linguística.

Essa pesquisa é realizada sob orientação da Profa. Dra. Olga Ferreira Coelho Sansone e está vinculada ao Centro de Documentação em Historiografia da Linguística (CEDOCH) do Departamento de Linguística da Faculdade de Filosofia, Letras e Ciências Humanas (FFLCH) da Universidade de São Paulo (USP) com apoio financeiro da Capes. 
Considerando a heterogeneidade das obras que compõem o nosso corpora, foi justamente essa "múltipla abordagem" mencionada por Swiggers que nos pareceu ser adequada para o tipo de material com o qual estamos lidando. Assim, é possivel analisar diferentes materiais linguístico-gramaticais sob diferentes pontos de vista ou, na terminologia do autor, camadas.

Nos limites deste texto, nós nos deteremos apenas à produção gramatical, por nós categorizada em dois grupos: as gramáticas escolares e as gramáticas de referência. Relativamente a esse universo, realizaremos um estudo pontual em relação ao conjunto total de obras e autores apresentados no projeto de doutorado. Como corpus, selecionamos duas obras de Said Ali (1861-1953), a Grammatica secundaria da Lingua Portugueza (1923) e a Grammatica historica da Lingua Portugueza (1931). A primeira representa o grupo das gramáticas escolares e, a segunda, o grupo de gramáticas que não foram produzidas visando ao uso escolar, ou seja, as de referência. A respeito dessa distinção, mais à frente nos encarregaremos de explicá-la.

Metodologicamente, os aspectos que objetivamos investigar nas referidas gramáticas são: 1. na camada teórica, se há ou não mudanças de ordem teórica quando se insere a gramática no universo escolar; 2 . na camada técnica, se tal inserção escolar altera ou não as maneiras de se analisarem e apresentarem os dados linguísticos; 3. na camada documental, se o tipo de documentação linguística utilizado pela gramática é alterado quando essa é usada no ambiente escolar; e, finalmente, 4. na camada contextual, se havia algo no cenário educacional brasileiro que pudesse interferir na produção gramatical.

\section{GrAMÁTICA DE REFERÊNCIA E GRAMÁTICA ESCOLAR}

Em termos gerais, podemos dizer que a gramática ocidental, desde sua origem, tem, como característica principal, a produção de reflexões a respeito de uma determinada língua e sua consequente transmissão àqueles que não possuíam tais conhecimentos, incluindo também nesse grupo, além dos já letrados, os mais jovens, que estavam iniciando nesse universo. Tais características conferem à gramática, por si só, um viés didático, independentemente dos diferentes matizes epistemológicos pelos quais passou ao longo dos séculos. No entanto, isso não nos autoriza a caracterizar a gramática como uma obra escolar, já que, para isso, teríamos que colocá-la no ambiente específico da escola, o que certamente não constituiu seu único lugar de uso ao longo da história.

No caso brasileiro, em especial, a relação entre a gramática - principalmente a não relacionada à alfabetização e às primeiras letras - e o universo da escola aparecerá com alguma relevância no final do século XIX e ganhará volume ao longo do século XX. Esse processo pode ser justificado pela tardia criação do ensino secundário no Brasil, que ocorreu apenas em 1837, e também pela pouca relevância que tinha a disciplina de Português no currículo desse período, que só foi alterado "depois de 1869, quando o exame de Português foi incluído entre os [exames] Preparatórios ${ }^{2}$ de muitos cursos superiores (faculdades de Direito, faculdades de Medicina, Escola Politécnica, Escola de Minas, etc.)” (RAZZINI, 2000, p. 238).

2 Os exames preparatórios eram as provas que habilitavam os alunos ao curso superior. Tais exames eram de responsabilidade do ensino secundário e antecederam o vestibular, que surgiu sob a responsabilidade das próprias instituições de ensino superior. 
Assim, classificamos como gramáticas escolares as obras que foram feitas exclusivamente para atender às necessidades dos alunos em sala de aula. Tais materiais têm indicações muito claras quanto ao seu uso, muitas vezes destacando seu atrelamento ao programa de ensino oficial vigente à época ou mesmo indicação expressa, em prefácios, por exemplo, de que se trata de material produzido para o aluno, com indicação de série e segmento da escolarização a que se destina o material. Também podemos encontrar outras características como a presença de questionário/exercícios sobre a teoria explanada e a ausência de citações de rodapé, local em que se apresentavam teóricos que fundamentavam e vinculavam doutrinariamente a gramática em questão.

Com efeito, essas obras são verdadeiros materiais didáticos, importantes ferramentas de auxílio do professor de Português, em um ambiente escolar que vai se ampliando e estruturando cada vez mais.

Justamente por esse seu viés bastante ligado à escola, julgamos necessário categorizar esse tipo de produção como gramática escolar, distinguindo-a, portanto, do tipo de gramática que não se destinava explicitamente ao universo da escola.

Adicionalmente, é importante verificar a definição de Swiggers (2012, p. 17) sobre a gramaticografia didática:

Por gramaticografia didática entendo a escrita de obras gramaticais com vistas a aprendizagem/ensino de uma (ou de várias) língua(s). [...] Aplicado à história da gramaticografia, me parece que é necessário definir o conceito de "didático" por duas características: (i) uma função utilitária, com vistas à aquisição de uma competência "lingual" (e não entrarei aqui na discussão em torno da distinção entre aquisição e aprendizagem) e (ii), de maneira muito mais implícita, a consideração dos níveis de competência linguística à qual se pretende chegar/ fazer chegar o aluno. (tradução nossa)

Por outro lado, classificamos como gramática de referência as obras que não têm como principal motivação o uso escolar, embora possam ser eventualmente ali utilizadas. Dessa forma, tinham como destinatários tanto o público em geral, não especializado, quanto os já iniciados na discussão gramatical, os pares. Esse aspecto faz que encontremos, nessas gramáticas, reflexões e discussões teóricas mais aprofundadas, destinadas não a alunos, mas sim a outros especialistas. Há também uma discussão técnica, muitas vezes de ordem teórica, doutrinária, tanto de assuntos gramaticais quanto os de ordem mais filológica. É evidente que tal aprofundamento destoa dos propósitos da escola, visto que o destinatário desse material deveria ser o aluno e não o professor.

\section{O ENSINO SECUNDÁRIO BRASILEIRO E A IMPORTÂNCIA DOS PROGRAMAS DE ENSINO DE PORTUGUÊS}

Para que possamos melhor compreender nossa proposta de divisão das gramáticas em escolares e de referência, precisamos, necessariamente, compreender a formação do ensino secundário brasileiro, o que ocorreu ao longo do século XIX, notadamente a partir de 1837, com a criação do Colégio Pedro II.

Quanto à análise da já mencionada influência dos programas de ensino sobre a produção gramaticográfica brasileira, precisamos também recuar ao século XIX 
e ao Colégio Pedro II, uma vez que é das mãos de um de seus docentes, Fausto Barreto (1852-1908), que surge, em 1887, o primeiro programa de ensino no país, batizado com o nome de seu autor.

\section{O Colégio Pedro II e a disciplina de Português}

Esse recuo ao século XIX precisa ser feito não só para olharmos aspectos diretamente ligados ao ensino secundário, mas também para alguns dados mais amplos sobre a educação brasileira em meados dos séculos XIX e XX. A verificação das taxas de alfabetização do país, por exemplo, nos fornece um aspecto relevante sobre o contexto de circulação das produções editadas no Brasil, uma vez que todo o universo em torno da produção de livros e dos demais materiais impressos ficava reduzido a uma pequena elite cultural, considerando que a maior parte da população não era alfabetizada. Quando um país decide expandir seu sistema de ensino, de maneira que atenda a números cada vez maiores da população, obviamente cria-se uma demanda por materiais de ensino que possam atender às especificidades pedagógicas de cada nível. Vejamos, então, dados relativos à alfabetização brasileira entre 1872 e 1950 .

Tabela 1 - A alfabetização brasileira entre 1872 e 1950

\begin{tabular}{|l|c|c|c|c|c|c|}
\hline População brasileira & $\mathbf{1 8 7 2}$ & $\mathbf{1 8 9 0}$ & $\mathbf{1 9 0 0}$ & $\mathbf{1 9 2 0}$ & $\mathbf{1 9 4 0}$ & 1950 \\
\hline $\begin{array}{l}\text { Sabe ler e escrever } \\
\text { \% sobre o total de } \\
\text { habitantes } \\
\text { considerados) }\end{array}$ & 1.564 .481 & 2.120 .559 & 4.448 .681 & 7.493 .357 & 10.379 .990 & 14.916 .779 \\
\hline $\begin{array}{l}\text { Não sabe ler e } \\
\text { escrever }\end{array}$ & 8.365 .997 & 12.213 .356 & 12.989 .753 & 23.142 .248 & 13.269 .381 & 15.272 .632 \\
\hline $\begin{array}{l}\text { Habitantes de 15 } \\
\text { anos ou mais* }\end{array}$ & - & - & - & $-24 \%$ & $49 \%$ \\
\hline $\begin{array}{l}\text { Habitantes de todas } \\
\text { as idades }\end{array}$ & 9.930 .478 & 14.333 .915 & 17.438 .434 & 30.635 .605 & 41.236 .315 & 51.944 .397 \\
\hline
\end{tabular}

* Os censos de 1940 e 1950 consideraram o grau de instrução da população de "15 anos ou mais". Fonte: Razzini (2000, p. 20).

O início de expansão do ensino secundário brasileiro não foi uma ação isolada, mas parte de um processo maior de "modernização cultural burguesa" pelo qual passava a sociedade brasileira. Razzini (2000, p. 22, grifo nosso) refere-se a esse processo de modernização ao afirmar que:

Ao longo do século XIX, nossa pequena classe dominante passou a apreciar cada vez mais as formas modernas de civilização burguesa. Porém, ao mesmo tempo, a aclimatação do modelo europeu de civilização tinha que conviver numa sociedade de estrutura colonial, assentada sobre a escravidão, cuja permanência sustentava a elite local e reproduzia o alheamento da maioria da população. Dentre as importações culturais europeias, destaca-se o modelo francês, que sempre exerceu entre nós grande fascínio durante o século XIX, prolongando-se até a metade do século XX. A França se fez presente desde o financiamento, por 
D. João VI, da "missão artística francesa", no início do século XIX, passando pela fundação de instituições nela inspiradas, como o Colégio Pedro II (1837) ${ }^{3}$, o Instituto Histórico e Geográfico Brasileiro (1838), a Academia Brasileira de Letras (1897), além de salões, clubes, teatros, associações, até a disseminação do consumo de bens importados, tais como arquitetura, decoração, companhias teatrais (e cocotes), moda, culinária, além, é claro, de muito material impresso (folhetins, romances, compêndios, etc.).

Ainda Razzini (2000, p. 24, grifo nosso), ao analisar as condições de surgimento do ensino secundário no Brasil, destaca, sobretudo, sua vocação original.

No século XIX, inicialmente "anexa" às faculdades de Direito e a outros cursos superiores, a escola secundária cresceu com o aumento da demanda dos cursos superiores, justificando o aparecimento de vários colégios, liceus, ginásios, ateneus, etc., e o desenvolvimento significativo de seu respectivo aparato (corpo docente, currículos e livros didáticos), logo controlado pelo estado. É neste contexto que surge e se destaca o Imperial Colégio de Pedro II.

Não é exagero dizer que o Colégio Pedro II passa, então, a exercer um papel nuclear no tocante à educação secundária no Brasil. A importância da instituição e de seus professores começa a balizar os rumos da escola secundária no Império e no início da República. Vejamos o que Razzini (2000, p. 27, grifo nosso) diz a respeito da influência dos docentes desse colégio:

O poder dos professores do Colégio Pedro II era hegemônico, se considerarmos que eram eles que decidiam, cada um na sua cátedra, o programa curricular e os compêndios adotados no colégio e, por conseguinte, nos exames preparatórios.

É nesse contexto que se cria um cenário proficuo para o surgimento de compêndios didáticos que atendessem, primeiramente, ao próprio ensino secundário, e, depois, aos exames preparatórios.

Não obstante ao cenário acima apresentado, de acordo com Razzini (2000), a disciplina de Português não gozava, inicialmente, de muito prestígio no currículo do referido colégio em função da importância que o ensino clássico ainda possuía. Nele preponderava o ensino de latim e de disciplinas como a retórica e a poética. É somente em 1869, no âmbito da reforma do ministro Paulino de Souza, por meio do Decreto $n^{\circ} 4.430$, de 30 de outubro, que institui a obrigatoriedade da prova de Português nos exames preparatórios, que a disciplina passa a ter maior importância no contexto do ensino secundário. Entretanto, esse decreto entrou em vigor apenas em 1871.

Além do referido decreto, podemos assinalar que a disciplina de Português recebeu outros dois grandes incentivos vindos inicialmente do Decreto $n^{\circ}$ 9.649, de 2 de outubro de 1886, e depois do Aviso $\mathrm{n}^{\circ}$ 974, de 17 de março de 1887, que institui o programa de Fausto Barreto.

Quanto ao primeiro, destaca-se que é esse decreto que institui a precedência do exame de Português sobre todos os outros, ou seja, o torna eliminatório. O segundo, Aviso $\mathrm{n}^{\circ}$ 974, determina qual programa de Português deve ser cobrado nos exames preparatórios em todo o Império. Assim, em conjunto,

3 Nesse momento, ainda chamado de Imperial Colégio Pedro II. 
essas duas determinações legais colocaram o conhecimento dos pontos exarados no programa de Fausto Barreto (doravante denominado PFB) como condição sine qua non a todos os alunos que desejassem ingressar nos cursos superiores, já que estariam presentes no exame de acesso a todos os cursos desse nivel de ensino.

Com efeito, é desnecessário dizer o quanto tal programa impactou a produção gramatical utilizada até então, uma vez que não era mais possivel deixar de estudar os pontos por ele apresentados. Haverá, portanto, uma adaptação dos compêndios já existentes ao PFB ou mesmo a produção de novas gramáticas a ele atreladas.

\section{As gramáticas sob impacto do programa de Fausto Barreto}

Podemos dizer que, antes da publicação do PFB, predominavam as gramáticas que categorizamos como de referência, já que o ainda incipiente ensino secundário não demandava produções escolares que pudessem atendê-lo em suas especificidades. Depois que veio a lume, deixar de atender tal programa não era algo que se mostrava prudente. Vejamos como Silva Junior e Andrade (1887, p. 3, grifo nosso), no prefácio das Noções de grammatica portugueza, se manifestam a respeito:

Tínhamos emprehendido escrever uma grammatica completa da língua portugueza, rompendo em lucta a tradição, e fazíamos fundamento de entregal-a em breve á publicidade. O novo programma para os exames geraes de preparatórios, porem, veio fazer-nos mudar do propósito. É que muitos dos pontos nelle exigidos para os exames de portuguez não se encontrando nas grammaticas que por ahi correm impressas, e os alumnos não tendo fontes onde possam haurir a instrucção de que carecem, resolvemos vir ainda uma vez em auxilio da mocidade estudiosa.

Cientes de que não estavam entregando uma gramática de referência, como desejavam fazer, mas sim uma gramática escolar, Silva Junior e Andrade (1887, p. 3) asseveram: "Não apresentamos este trabalho como merecedor de gabos de excellente, nem no intuito de nos revelarmos professores de sciencia jubilada. $\mathrm{O}$ tempo urgia; bosquejamos apenas o assumpto".

Essa mudança de planos não parece ter agradado aos autores, que continuam o registro dessa contrariedade no prefácio. Vejamos: "Nem sempre o nosso parecer coincidiu com a indicação do programma official; seguimos todavia, para maior segurança dos viajantes noveis, o roteiro apresentado pelo governo". Os gramáticos parecem ter clareza daquilo que observa Bittencourt (2004, p. 479): "O autor de uma obra didática deve ser, em princípio, um seguidor dos programas oficiais propostos pela politica educacional".

Passado um ano da publicação de sua gramática, Pacheco da Silva Júnior ${ }^{4}$ (1842-1899), agora em coautoria com José Ventura Boscoli (1855-1919), publica um livreto a ela complementar, para então deixar esses dois materiais adaptados o máximo possivel à realidade escolar da época. Vejamos o que diz, no prefácio, o autor sobre o motivo de tal publicação:

4 Pacheco da Silva Junior foi catedrático do Colégio Pedro Il e sua gramática foi adotada pela escola entre 1893 e 1898. 
Escrevemos este livrinho porque se nos afigurou de grande utilidade para os estudantes de preparatorios, obrigados tambem, na prova oral, a uma analyse syntaxica, phonetica e etymologica. [...] Só nos reportámos, no correr da primeira parte deste livrinho, ás Noções de Grammatica Portugueza por ser esse trabalho incontestavelmente o mais completo sobre os pontos oraes, tanto assim que foi premiado pelo Conselho pedagogico, e acaba de ser adoptado no Imperial Collegio de Pedro II, para o $5^{\circ}$ anno (exame final). Para organização da segunda parte, porém, compulsámos diversas producções grammaticaes e philologicas, entre as quaes avultam as de Julio Ribeiro, Fausto Barreto, G. F. Holms, A. Grivet, A. Bain (SILVA JUNIOR; BOSCOLI, 1888, prefação).

Mesmo os gramáticos das chamadas gramáticas de referência, como Júlio Ribeiro (1845-1890), que não produziu sua Grammatica portugueza com fins escolares, ao ver publicado o PFB em 1887 - seis anos depois da primeira edição de sua obra -, reivindica o título de ser o seu compêndio o único a atender à doutrina e aos pontos do programa.

Si foramos vaidoso, era esta a hora de rejubilar: o programma de Portuguez, bem como os de todas as outras linguas que se ensinam oficialmente no Brasil, está de accordo exacto, perfeito com os principios da grammatica scientifica, que, em 1881, tivemos a ousadia de arrojar á publicidade. Hoje abundam em Portuguez monografias linguisticas valiosissimas; temos a primeira parte da monumental grammatica historica de Pacheco Junior; Adolpho Coelho, Leite de Vasconcellos, João Ribeiro, Fausto Barreto, Lameira de Andrade brilham como astros de primeira grandeza no céo da nossa filologia: mas, ainda assim, é a nossa Grammatica a unica grammatica por onde se possa preparar um alumno para enfrentar com o actual programma de exames (RIBEIRO, [1935?], p. 93) ${ }^{5}$.

Ribeiro $^{6}$ não era professor do Colégio Pedro II, mas teve lá sua gramática adotada por breve período, em 1882. Como destacou Razzini (2000), a maioria dos compêndios adotados nesse prestigioso colégio foram escritos por seus catedráticos, como foi o caso de João Ribeiro (1860-1934), Fausto Barreto ${ }^{7}$ (1852-1908) e Antenor Nascentes (1886-1972).

Além de atenderem ao que estabeleciam os programas de ensino, as gramáticas escolares e os demais materiais ligados a ela passam a se moldar a esse ambiente, que se tornou cada vez mais especializado. O contraste com as gramáticas de referência aponta para suas especificidades, como: questionário/ exercícios sobre a teoria explanada; indicação expressa, em prefácios, por exemplo, de que se trata de material destinado ao aluno; indicação de série; segmento da escolarização a que se destina o material; ausência de citações de rodapé, em que se traziam teóricos que fundamentavam e vinculavam doutrinariamente a gramática em questão.

Se houve, então, tal profusão de gramáticas escolares, cabe, a partir dessa constatação, uma análise para verificar suas características comparativamente às gramáticas de referência.

5 Ribeiro publicou seus textos no jornal A Procellaria, em 1887. O livro homônimo, no entanto, foi lançado cerca de 30 anos depois, reunindo todos os textos publicados pelo autor nos referidos jornal e ano.

6 Ribeiro foi professor, entre outros lugares, do Colégio Culto à Ciência, em Campinas, SP.

7 No caso de Fausto Barreto, a adoção não foi de uma gramática, mas sim da Anthologia nacional ou coleção de excerptos, escrita em parceria com Carlos de Laet. 
Feitas as considerações ligadas à camada contextual, passemos, no próximo item, às análises das outras três camadas.

\section{BREVE CONTEXTO RELATIVO AOS MODELOS PRESCRITIVISTA E HISTÓRICO-COMPARADO}

A obra que se enquadra nas características que definimos para o grupo das gramáticas de referência é a Grammatica historica, de 1931. Para o grupo das gramáticas escolares, usaremos a Grammatica secundaria, de 1923. A respeito dessas obras, é importante destacar que elas estão ligadas a modelos epistemológicos diferentes. Enquanto a primeira se utiliza de conceitos e práticas da gramática histórico-comparada, a segunda segue o modelo prescritivista.

O prescritivismo teve sua origem na Antiguidade clássica, sendo a gramática grega Tékhne Grammatiké, atribuída a Dionísio Trácio (I a. C.), considerada a primeira da tradição ocidental. A seu respeito, Borges Neto (2012, p. 88, grifo nosso) assim se manisfesta:

Chamo de gramática tradicional a teoria das línguas humanas surgida na Antiguidade clássica e que se mantém essencialmente igual até os nossos dias, dando forma às gramáticas escolares, por exemplo. Essa teoria tem sua formulação completada já na Idade Média e é base do pensamento sobre as linguas humanas em, pelo menos, todo o mundo ocidental.

Com efeito, podemos dizer que a gramática tradicional é uma teoria que tem como concepção geral a prescrição de regras que visam a ensinar a falar e a escrever corretamente.

Nesse sentido, a gramática trabalha com um modelo de lingua considerado por ela adequado e valoroso. Qualquer forma linguística que estiver fora desses referenciais é considerada incorreta e deve ser, portanto, corrigida. Tais características explicam, como assinalou Borges Neto, o motivo de as gramáticas escolares se valerem, há séculos, desse modelo gramatical. Nos termos de Swiggers (2004), podemos dizer que aqui caracterizamos a camada teórica do prescritivismo.

Quanto à camada técnica, como nos lembra Borges Neto (2012, p. 89, grifo nosso), esse modelo tem como unidade principal de análise a palavra.

[...] as análises propostas pelos gramáticos [da gramática tradicional = GT] devem seguir determinadas linhas de raciocinio (e obedecer aos pressupostos) para que sejam aceitas como análises "legais" dentro de seu quadro teórico. A GT assume que a palavra é a unidade de análise (nada há abaixo da palavra) e que a oração (sentença, proposição, frase, a depender do autor) é uma construção de palavras. Na oração, as palavras recebem certa ordenação (sintaxe) para que a oração consiga exprimir um pensamento completo e cada palavra na medida em que representa uma ideia - contribui, na oração, para que esse pensamento seja obtido. Cabe à sintaxe, então, mostrar como as ideias contidas nas palavras devem ser ordenadas para que se chegue ao pensamento veiculado pela oração. O estudo das palavras envolve, basicamente, duas coisas: sua classificação e sua "morfologia".

Em relação à camada documental, o modelo prescritivista se vale, predominantemente, de textos literários clássicos, uma vez que eles eram vistos como o principal meio de atingir os estados antigos da lingua, nos quais estavam, segundo essa visão, os usos "corretos" da lingua, como bem destacou Borges 
Neto (2012). A gramática histórico-comparada, por outro lado, desenvolveu-se ao longo do século XIX, a partir dos estudos de autores como Friedrich Schegel (1772-1829), Franz Bopp (1791-1867) e Jacob Grimm (1785-1863). No caso específico do português, são importantes os estudos do linguista alemão Friedrich Diez (1794-1876), já que é ele "quem inicia os estudos da chamada filologia (ou linguística) românica, nome que se deu ao estudo histórico-comparativo das linguas oriundas do latim" (FARACO, 2005, p. 136-137).

$\mathrm{Na}$ sequência, o autor aponta para um aspecto amplamente utilizado nas obras ligadas ao modelo histórico-comparado, como é o caso da Grammatica historica: o recurso ao latim para realizar os estudos sobre o português.

A filologia românica teve um papel fundamental no desenvolvimento dos estudos histórico-comparativos. Enquanto em outras subfamílias só se alcançam os estágios mais antigos por reconstrução hipotética em razão da inexistência de registros escritos, na subfamília românica a documentação em latim é extensa, o que permitiu um importante refinamento metodológico dos estudos históricos: com uma situação em que as formas ascendentes são atestadas, foi possível reforçar a confiabilidade nos procedimentos do método nos casos em que isso não ocorria (FARACO, 2005, p. 137).

Dessa forma, podemos observar que tal modelo altera, em relação ao prescritivismo, os procedimentos utilizados nas camadas técnica e documental. A técnica de análise linguística passa a ser a da reconstrução histórica, utilizando-se para tal empreitada a comparação entre diferentes línguas (método comparativo) ou a comparação entre textos de uma mesma língua, porém de diferentes sincronias (método histórico). Quanto à documentação utilizada, não há mais a preocupação com a busca de textos que abonem os "bons usos", mas sim de materiais que possam reconstruir uma determinada lingua, o que pode incluir textos literários, mas não apenas esses.

Tais procedimentos indicam claramente que, na gramática histórico-comparada, há uma concepção de língua bastante diferente daquela encontrada na gramática tradicional, já que o que está em jogo é a necessidade de se encontrar a origem e compreender a evolução das línguas, e não mais o "certo e errado". Com efeito, tais aspectos estão ligados à camada teórica do modelo ora em análise.

Em relação aos estudos histórico-comparados no Brasil, Faraco (2018, p. 48) explica em que bases se deu o surgimento da gramática histórica no Brasil.

O novo paradigma [refere-se à Gramática Histórico-Comparativa], associado à própria criação de uma nova ciência da linguagem, instaurava, portanto, um discurso forte que procurava escrupulosamente separar o científico do que considerava como não científico. [...] este novo paradigma entrou no Brasil na década de 1870 pelas mãos de Pacheco da Silva Jr., seja com seu livro de Fonologia (1877), seja com sua gramática histórica (1878), a primeira a ter esse título em língua portuguesa [...]. Será sob esse paradigma que os estudos linguístico-históricos se desenvolverão no Brasil durante quase um século.

\section{As gramáticas de referência e escolar de SaId Ali}

Já apontamos na seção anterior que utilizamos a Grammatica historica, de 1931, como representante do grupo das gramáticas de referência e a Grammatica secundaria, de 1923, como obra ligada ao universo das gramáticas escolares. 
A respeito da Grammatica historica, é importante salientar que ela resulta da junção de dois livros publicados anteriormente por Said Ali: Lexeologia do Portuguez historico, de 1921, e Formação de palavras e syntaxe do Portuguez historico, de 1923. Muito provavelmente por questões de ordem comercial, em 1931, a Editora Melhoramentos resolve juntar esses dois livros sob o título de Grammatica histórica da Lingua Portugueza. Aqui o uso do termo juntar é exato, pois com exceção do deslocamento de dois capítulos escritos na Formação de palavras para o início da Lexeologia, o restante da Grammatica historica é exatamente a junção sequencial desses dois livros de Said Ali, seguindo a ordem de publicação original.

Sobre o que considera ser a gramática histórica, Said Ali (1923, p. 5) assim se manifesta: "Grammatica historica é aquella que estuda a evolução dos diversos factos da língua desde a sua origem até a epoca presente". Já a respeito do que entende por gramática descritiva, Said Ali (1923, p. 5) afirma:

A grammatica descriptiva é a que expõe os factos da lingua actual. A grammatica descriptiva é pratica quando tem principalmente em vista ensinar a falar $e$ a escrever correctamente; é scientifica quando procura esclarecer vários factos á luz da sciencia da linguagem e da grammatica histórica.

Nos trechos selecionados, fica evidente a importância dada por Said Ali aos estudos históricos da língua, que ele classifica como científicos. Nesse sentido, podemos afirmar que, para o autor, o fazer científico em matéria gramatical consistia em explicar os fatos linguísticos sincronicamente observáveis pelo recuo a outras fases históricas da língua. A esse fazer científico, podemos relacionar a produção das gramáticas de referência. No que tange à gramática escolar, seu conceito pode ser visto quando Said Ali define grammatica descriptiva prati$c a$, que, para o autor, deve ser a responsável por "ensinar a falar e a escrever correctamente".

Para que possamos fazer o estudo referente às camadas teórica, técnica e documental, selecionamos um mesmo tópico a fim de verificar como ele é tratado na gramática histórica (de referência) e na secundária (escolar). Selecionamos, para tal tarefa, trechos das respectivas seções em que ocorre o estudo sobre o processo da alternância vocálica e também sobre as vogais nasais.

A Grammatica historica tem os assuntos ligados à fonologia divididos em dois capítulos: um chamado "As alterações phoneticas do latim vulgar" e, na sequência, outro intitulado "Os sons em portuguez e sua representação". Desse último, retiramos os trechos analisados neste artigo.

Vejamos como Said Ali (1931, p. 20) diferencia os dois capítulos:

Cabe á grammatica historica traçar e explicar, primeiro que tudo, as diversas modificações por que passaram os phonemas de uma lingua no decorrer dos seculos. Da phase primitiva tratámos nas paginas precedentes. Daqui em diante teremos de atender ao objectivo bem definido da presente obra. Só incidentemente nos occuparemos da epoca durante a qual o latim ou romanico, em certa parte da peninsula iberica, se foi transformando em idioma portuguez. Não cotejaremos phonetica portugueza com phonetica latina, e sim textos portuguezes com textos portuguezes, os quaes durante longo periodo não oferecem á pesquisa phonetica outra informação mais que as letras representadoras dos phonemas. 
Nesse ponto, já podemos destacar uma diferença substancial entre as gramáticas do autor. Na gramática secundária, o primeiro capitulo sobre "As alterações phoneticas do latim vulgar" é eliminado. Em relação ao segundo capítulo, em que se estudam os sons do português, passaremos agora a analisar seu conteúdo.

\section{Alternância vocálica}

Said Ali (1931, p. 140), em sua Grammatica historica, assim se manifesta a respeito do que entende por alternância vocálica: "Damos este nome á mudança soffrida pela vogal thematica em certas formas rhizotonicas". Já na Grammatica secundaria, aparece a seguinte definição: "Muitos verbos soffrem mudança na vogal do radical quando neste recae o acento tonico" (SAID ALI, 1923, p. 113).

Ao analisarmos a seção "alternancia vocalica" da Grammatica secundaria, encontramos algo que já apontamos anteriormente quanto ao tratamento das "vogaes nasaes": um texto bastante sintético ${ }^{8}$, direto e sem maiores explicações a respeito dos processos linguísticos ali apresentados.

Considerando que o autor não se detém em explicações mais detalhadas, basicamente, o assunto é tratado pelo uso de listas de palavras em que ocorre ou não a alternância vocálica. Após a definição sobre o processo no início da seção e reproduzida anteriormente por nós, seguem-se os exemplos e listas a que nos referimos. A seguir, apresentam-se algumas ocorrências, retiradas da obra de Said Ali (1923, p. 113):

Em rogar trocamos ô fechado em ó aberto para dizer rogo, rogas, roga. Semelhantemente convertemos ê fechado em é aberto para dizer levo, levas, bebes, bebe. De subir usamos as formas subo, sobes, sobe; de servir, sirvo, serves, serve. [...] Os verbos que alternam u com o, e i com e vêm especificados na lista dos verbos irregulares.

Na sequência, o autor faz uma observação de caráter restritivo quanto à amplitude da abordagem que será dada ao assunto: "Aqui tratamos sómente da mudança do ô fechado em ó aberto, e de ê fechado em é aberto" (SAID ALI, 1923, p. 113, grifo nosso). Em seguida, o autor apresenta situações em que não ocorre a alteração vocálica: "Conserva-se a vogal fechada, quer dizer, não ha alternância vocalica: $1^{\circ}$ quando a vogal tonica se acha no fim do radical: crê, crês; lês, lê; dês, dê; vês, vê" (SAID ALI, 1923, p. 113). Depois desse primeiro caso, seguem-se outros cinco, sequencialmente, em tópicos.

Feitas as ressalvas, Said Ali (1923, p. 114) apresenta outras situações nas quais efetivamente ocorre a alternância:

Exceptuados estes casos, verifica-se regularmente que a vogal tonica e ou o converte-se de fechada em aberta na $2^{a}$ e $3^{a}$ pessoa do singular e $3^{a}$ do plural do presente do indicativo, bem como na $2^{a}$ do singular do imperativo, tanto nos verbos em -ar e -ir. Exemplos: governar: governas, governa, governam, governa. Negar: negas, nega, negam, nega. [e assim, sucessivamente, para uma lista de outros onze verbos].

Ao longo dessa seção, o autor não oferece nenhuma explicação sobre o processo da alternância vocálica, não recorrendo a nenhuma análise histórica, nem

8 Na gramática secundária, o tema é estudado em duas páginas e meia, ao passo que na histórica, em cinco. 
de como as diferentes pronúncias do português, no Brasil e em Portugal, modificam a alternância vocálica. Tais expedientes são utilizados apenas em sua Grammatica historica e é o que examinaremos a seguir.

Ao selecionarmos os trechos para análise, optamos por escolher um relativo a um tópico que na Grammatica secundaria não foi desenvolvido, mostrando, assim, a maior amplitude analitica da Grammatica historica. Said Ali (1923, p. 113, grifo nosso) diz que ali tratará "[...] sómente da mudança do ô fechado em ó aberto, e de ê fechado em é aberto". Dito isso, prossegue, apontando que "os verbos que alternam $u$ com $o$, e $i$ com $e$ vêm especificados na lista dos verbos irregulares".

Na Grammatica historica, Said Ali (1931, p. 143, grifo nosso) realiza um estudo mais detalhado e completo sobre a alternância vocálica, o que inclui, evidentemente, os casos excluídos da secundária. Vejamos:

Mudança de o em u verifica-se em durmo e durma, durmas etc. do verbo dormir e nas formas de $l^{a}$ pessoa puz, pude (lat. posui, potui) ao lado das de $3^{a}$ pessoa poz, poude. Mudança de e para i dá-se na $l^{a}$ do singular do presente do indicativo (e todo o presente do conjuntivo) de alguns verbos pertencentes á conjugação em ir: firo (< port. ant. *fero < feiro); sigo, sinto (e compostos destes tres verbos); dispo, visto, minto e advirto. A alternância estendeu-se a principio ás demais rhizotonicas do indicativo e a outros verbos da mesma conjugação. Vestigios disto são, no portuguez antigo, os imperativos pidi (por pide) (S. Josaph. 16), e viste-te (ib. 13); e no portuguez mod., os imperativos minte-lhe (G. Vic. 1, 303), prosigue tu, (ib. 1, 319), viste-te da sua lam (H. Pinto 1, 176), dá e fire quanto quiseres (ib. 1, 45), sigue-me firme e forte (Cam., Lus. 10, 76), e o singularissimo indicativo prosigue em port. Mod. (Castro, Ulys. 10, 49).

Nesse trecho, evidencia-se o que Said Ali aponta como tarefa da gramática histórica, ou seja, o recuo a outras fases da lingua para que se possa explicar a língua do presente. Nota-se aqui claro interesse em explicar o processo linguístico em toda a sua constituição e não apenas em citar as situações em que tal fenômeno ocorre e em quais não ocorre, procedimento encontrado na Grammatica secundaria.

Outra marca dessa intenção de explorar o tema em toda a sua amplitude pode ser vista nas observações de ordem sociolinguística feitas pelo autor quando alguma diferença entres as variedades brasileira e lusitana do português interferia na análise de algum aspecto da alternância vocálica em exame.

A seguir, apresenta-se mais um trecho corroborando essa afirmação, retirado de Said Ali (1931, p. 141, grifo nosso):

[...] e actua finalmente como obstaculo á alternancia, em falar brasileiro, a consoante nasal posta immediatamente depois da vogal: gema, tema, ordenha, comes, tomam, etc. NOTA. - No falar lusitano a tonica o soa como vogal aberta, em come, tomas, etc.

\section{Vogais nasais}

Passemos agora para outro tema selecionado para análise, as vogais nasais. Nesse tópico, fica também evidente aquilo que apontamos quanto ao tratamento dado pelas duas gramáticas à alternância vocálica. Na Historica, há uma análise ampla do fenômeno linguístico que recorre aos dados diacrônicos para compreensão da sincronia e, na Secundaria, há apenas a prescrição gramatical, sem a preocupação em contextualizar ou explicar em detalhes o motivo de aquela de- 
terminada prescrição ser daquela forma. Com efeito, é preciso sublinhar que tal diferença pode ser explicada pelos diferentes objetivos que cada modelo epistemológico aqui apresentado possui.

Vejamos, então, como as vogais nasais são tratadas na Grammatica historica:

As vogaes $\left(\tilde{a}, e^{\sim}, \tilde{i}, \tilde{o}, u^{\sim}\right)$ procedem em geral de vogaes puras que tomaram antecipadamente a nasalidade de $\mathrm{m}$ ou $\mathrm{n}$, desaparecendo a articulação destas consoantes. Observa-se o phenomeno nos monosyllabos tam, quam, cum (com), sum (som), mas não se verifica na maior parte dos vocabulos que na lingua-mãi se escreviam com m terminal, porquanto, para taes casos, já nesta lingua se havia dado a redução da pronuncia da consoante final. (Veja-se a este respeito Sommer, Handbuch, $\$ \S 166$ e 176, 5). Vogal nasal proveniente da absorpção de $\mathrm{n}$ seguido de outra consoante, é facto normal em portuguez, como em outros idiomas romanicos: cĩ co (cinco), dãsa (dança), mãso (manso), pe sar (pensar), frãgo (frango), domi go (domingo), mõje (monje), trõco (tronco), etc. (SAID ALI, 1931, p. 25).

Mais adiante, a formação do ditongo -ão é analisada:

Semelhantes entre si, mormente se não eram oxytonas, as finaes -õ e-ã deviam confundir-se ao cabo de certo tempo. Accelerou o processo o juntar-se a ã a vogal o, dando o ditongo -ão. Assim diversificavam em Livro de Esopo 27 e 28 leom e leam, $e$, entre os quinhentistas, se escreve na mesma linha estavam $e$ tornavão (H. Pinto 1,97), andam $e$ andão (ib. 1, 98), descobrirão e ganharam (ib. 1, 99), sem contar virám (futuro), choram, hiam, nam, sam (b. 1, 256). As duas edições dos Lusiadas de 1572 empregam como diferença que mais dá nos olhos, segundo a frase de Epiph. Dias, uma, de preferencia a graphia-ão, a outra-am tanto nas syllabas atonas como nas tonicas. Em tempo de Vieira as duas terminações se usavam indiferentemente (...). Notavel é o desaparecimento da terminação -om, usualissima em port. ant. e que se conserva na linguagem moderna, dos quinhentistas em diante, sómente em bom, dom, som, trom, com $e$ tom (SAID ALI, 1931, p. 25-26).

Em sua Grammatica secundaria, Said Ali (1923, p. 10), a respeito das "vogaes nasaes", fornece uma breve explicação, de caráter puramente prescritivo. O autor apresenta apenas este trecho e, na sequência, passa a falar sobre as consoantes:

Cada uma das vogaes pode ser produzida tanto por simples resonancia da boca, como por dupla resonancia, atravessando parte da columma de ar as fossas nasaes. Quer dizer, a cada vogal oral corresponde outra nasal. A nasalização requer emtanto menos esforço para as vogaes fechadas que para as abertas, $e$ em nosso idioma brasileiro ocorre sómente a serie das nasaes fechadas (ã, $\tilde{e}, \tilde{\imath}$, o, ũ) (SAID ALI, 1923, p. 10).

\section{CONSIDERAÇões FinaIS}

Como já apontamos anteriormente, Faraco (2018, p. 48) refere-se ao surgimento, no século XIX, de um

[...] novo paradigma [Gramática Histórico-Comparada], associado à própria criação de uma nova ciência da linguagem. [Isso] instaurava, portanto, um discurso forte que procurava escrupulosamente separar o científico do que considerava como não científico. 
Em relação aos estudos sobre o português que eram feitos no Brasil no início do século XX, podemos dizer que esse novo paradigma encontra representatividade nos trabalhos realizados aos moldes da Grammatica historica, de Said Ali. Isso não ocorre com a Grammatica secundaria, volume em que o autor não recorre aos estudos históricos para "expor os factos da lingua actual", segundo sua definição de "grammatica descriptiva scientifica",

Said Ali dizia que a "grammatica pratica", ou seja, nesse caso, sua própria Grammatica secundaria, tinha como objetivo "principalmente ensinar a falar e a escrever correctamente", o que pode ser uma explicação para sua opção de, no cenário escolar, optar pelo modelo prescritivista, em detrimento dos estudos históricos, que tanto marcaram sua obra.

Nesse sentido, podemos afirmar que o surgimento de um novo paradigma na ciência da linguagem alterou o cenário gramaticográfico brasileiro quanto à camada teórica: enquanto as gramáticas escolares permaneceram ligadas ao modelo teórico prescritivista, as gramáticas históricas trouxeram ao estudo do português outro modelo epistemológico, o da gramática histórico-comparada. Apesar de o ensino escolar estar ligado tradicionalmente ao modelo prescritivista, o prestígio do novo modelo fez que os estudos gramaticais de viés histórico entrassem também no currículo da escola brasileira, embora devidamente circunscritos a anos específicos, como foi o caso do quarto ano do ginasial.

Em relação à camada técnica, como já apontamos, o surgimento da gramática histórico-comparada trouxe ao cenário gramaticográfico brasileiro novas técnicas de análise linguística, fundamentalmente, as mais ligadas ao historicismo. Assim, torna-se bastante frequente a comparação entre textos de diferentes fases do português, além do recuo ao latim, para que, através desses estudos, fosse possivel compreender melhor o português do presente.

Quanto à camada documental, em ambos os modelos, o texto literário, principalmente os mais antigos, possui grande peso, porém seu uso encontra diferentes propósitos. Na gramática tradicional, o texto literário clássico é usado para prescrever os usos considerados modelares, corretos, já, na gramática histórico-comparada, a literatura mais antiga é a comprovação dos estágios evolutivos pelos quais a língua passou até chegar à fase atual, não tendo, portanto, o objetivo prescritivo. Esquematicamente, podemos dizer que ambos os modelos fazem uso do mesmo tipo de documentação linguística, embora com propósitos bastante diferentes.

Finalmente, parece-nos que a presença, no início do século XX, de dois modelos epistemológicos diferentes, acabou gerando uma certa divisão do trabalho nos estudos sobre o português: o modelo prescritivista permanece ligado ao universo escolar e a gramática (ou linguística) histórico-comparada é desenvolvida em espaços que eram vistos como científicos, isto é, aqueles em que os professores, os gramáticos e os estudiosos do português circulavam, dialogando, portanto, com um público já iniciado, especializado. Esse tipo de produção não ficou restrito às gramáticas históricas, mas encontrou amplo terreno nas mencionadas obras monográficas mencionadas, nas quais temas específicos podiam ser explorados de forma mais ampla e profunda do que ocorria no compêndio gramatical. 


\title{
SAID AlI's REFERENCE AND SCHOOL GRAMMARS: A CASE STUDY ON BRAZILIAN GRAMMAR IN THE EARLY TWENTIETH CENTURY
}

\begin{abstract}
The present work aims to contribute to the characterization of Brazilian grammar of the beginning of the 20th century. Our hypothesis is that the grammar, in this period, loses the centrality in the discussions about the Portuguese that it had until then and becomes a type of publication with a more school bias. In this new scenario, the more in-depth discussions, aimed at specialists, in pairs, seem to move to works of a monographic character, which are increasingly published. For this endeavor, we carried out a specific study using two grammars by Said Ali, Secundaria (1923) and Historica (1931). In theoretical-methodological terms, we use the assumptions present in Swiggers (2004).
\end{abstract}

Keywords: Linguistic historiography. Gramaticography. Said Ali. 20th century. Grammatical epistemology.

\section{REFERÊNCIAS}

BITTENCOURT, C. M. F. Autores e editores de compêndios e livros de leitura (1810-1910). Educação e Pesquisa, v. 30, n. 3, p. 476-491, set./dez. 2004.

BORGES NETO, J. Gramática tradicional e linguística contemporânea: continuidade ou ruptura? Todas as Letras, São Paulo, v. 14, n. 1, p. 87-98, 2012.

FARACO, C. A. Lingüística histórica: uma introdução ao estudo da história das línguas. São Paulo: Parábola Editorial, 2005.

FARACO, C. A. Breve retrospectiva do pensamento linguístico-histórico no Brasil. In: CASTILHO, A. T. História do português brasileiro. São Paulo: Contexto, 2018. v. 1 , p. 33-71.

RAZZINI, M. P. G. O espelho da nação: a Antologia nacional e o ensino de português e literatura (1838-1971). 442 f. 2000. Tese (Doutorado em Teoria Literária) - Universidade Estadual de Campinas, Campinas, 2000.

RIBEIRO, J. Procellarias. São Paulo: Edições Cultura Brasileira, [1935?].

SAID ALI, M. Grammatica historica da Lingua Portugueza. São Paulo: Melhoramentos, 1931.

SAID ALI, M. Grammatica secundaria da Lingua Portugueza. 3. ed. São Paulo: Melhoramentos [s/d]. [1. ed. 1923].

SILVA JUNIOR, P. da; ANDRADE, L. de. Noções de grammatica portuguesa. Rio de Janeiro: J. G. de Azevedo-Editor, 1887.

SILVA JUNIOR, P. da; BOSCOLI, J. V. Noções de analyse. Rio de Janeiro: Imprensa Nacional, 1888.

SWIGGERS, P. Modelos, métodos y problemas en la historiografia de la lingüística. Nuevas aportaciones a la historiografía lingüística. In: CONGRESO INTERNACIONAL DE LA SEHL, 4., 2003, La Laguna (Tenerife). Actas... La Laguna (Tenerife), 2004. p. 113-146.

SWIGGERS, P. Historiografia de la gramaticografia didáctica: apuntes metodológicos con referencia a la (historia de la) gramática española y francesa. In: RUBIO, N. V. (org.). Lengua, literatura y educación en la España del siglo XX. Lleida: Peter Lang, 2012. p. 15-37. 